\title{
Risk from vibration in Indian mines
}

\begin{abstract}
Equipment-induced vibration is widely recognized as a health hazard. It is a physical stressor to which many people are exposed at workplace. Mining industry is no exception. In spite of extensive research undertaken in the developed countries, information on the magnitude of the problem in India is not available. An estimated 1 million workers were engaged in the Indian mining industry in the year 2003. The actual figures could be much higher. Analysis of employees' database of several mines reveals that $18 \%$ employees in the Indian mining industry are occupationally exposed to vibration. Large-scale mechanization considerably adds to the severity and complexity of the problem because of 1 ) increase in the percentage of exposed population and 2) longer duration of exposure. The clinical picture and health outcomes of exposure to hand-arm vibration and whole-body vibration are scantily documented in the Indian context. In view of the health risk and action taken in other countries, we submit that there is an urgent need to develop a practical management strategy for evaluation, monitoring and control of equipment-induced vibration in the mining industry.
\end{abstract}

Key words: Hand-arm vibration, Indian mining industry, legislation, occupational health, whole-body vibration

\section{INTRODUCTION}

Vibration is defined as oscillatory motion. Oscillatory displacement involves alternate velocity in one direction and then a velocity in the opposite direction. This change of velocity means that the object is constantly accelerating, first in one direction and then in the opposite direction. ${ }^{[1]}$ The oscillatory motion from a source, e.g., a vehicle or a tool, may be simple harmonic sine wave or a multiple wave complex differing in frequency and acceleration, or a random nonrepeating series of complex waves. ${ }^{[2]}$

In 1977 the International Labor Office (ILO) listed vibration as an occupational hazard and recommended that 'measures have to be taken to protect employees from vibration and the responsible authorities have to establish criteria to determine the danger; when necessary, the exposure limits must be defined by means of these criteria. Supervision of employees exposed to occupational hazard as a result of vibration at their places of work must also include a medical examination before the beginning of this particular job, as well as regular checkups later on.'

The problem is inherent to large-scale mechanization and is responsible for severe ill health. The present article is an effort to review the problem and evaluate the risk of vibration from the perspective of mining industry in our country.

\section{Health impacts}

The human responses to vibration depend on the part of the body that is exposed. There are two broad types of vibrations that workers are exposed to:

- Vibration transmitted to the whole body (whole-body vibration or WBV) through a supporting surface, for example, the feet of a standing person or the buttocks of a seated person

- Vibration applied to a part of the body, i.e., segmental vibration. When vibration is applied to the hand, it is termed as 'hand-arm vibration' or HAV.

Whole-body vibration and segmental vibration need to be studied separately because they are measured and evaluated using different standards. They also require different control measures and have differing effects on the human body.

The earliest literature available on health impact of vibration chiefly refers to the miners. The widespread use of jackhammers in the mining industry is a potential source of hazardous vibration affecting limbs in
Bibhuti B. Mandal, Anup K. Srivastava National Institute of Miners' Health, Nagpur, India

For correspondence: A. K. Srivastava, National Institute of Miners' Health, JNARDDC Campus, Amaravati Road, P.O. Wadi, Nagpur - 440023 , India. E-mail: srianup1@yahoo.co.in

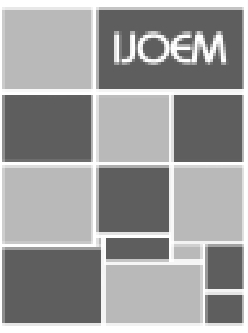


the human body. Jackhammers are used both in opencast and underground mines; and the operators, popularly known as drillers, are regularly exposed to hand-arm vibration (HAV). Vibrating hand tools like hand drills, chipping machine, riveting guns ${ }_{i}$ control systems of modern large drill machines, locomotive handles; and hand-held grinders, scrapers, etc., are other sources of HAV exposure in mines.

Regular exposure to vibration causes both vascular and neural disorders. Involvement of arms manifest as vibration-induced white finger (VWF) or hand-arm vibration syndrome (HAVS). In 1911 Giovanni Loriga of Italy first reported HAVS among stone cutters using pneumatic hammers on marble and stone blocks. ${ }^{[1]}$ They suffered from finger-blanching attacks similar to the digital vasospastic response to cold or emotional distress, described by Raynaud ${ }^{[3]}$ in 1862. Later in the U.S, it was found to result from daily use of vibrating pneumatic hand tools (air-hammers) by workers in limestone quarries of Indiana. ${ }^{[4]}$ Pelmear and Wasserman ${ }^{[5]}$ summarized the clinical symptoms. These are:

1. Tingling and/or numbness in the finger(s) initially - similar to but not same as Carpel Tunnel Syndrome.

2. As the exposure continues, the appearance of a single white or blanched fingertip occurs - usually, but not always - in the presence of cold.

3. With further exposure, these attacks increase in number, intensity and duration, especially in cold conditions. In the later stages, HAVS attack will occur in all seasons. Simultaneous combination of vibration, cold and nicotine (from smoking) are particularly harsh since all three tend to act as synergistic vasoconstrictors. Later stages of HAVS are generally irreversible.

4. In extreme and rare cases, the loss of blood supply to the fingers can lead to gangrene, which may require amputation.

The existence of sensory and vascular components in HAVS led to the adoption of the Stockholm grading based on the subjective history supported by the results of clinical tests to classify the severity [Table 1].

In South Africa, the prevalence rate of HAVS is estimated at $15 \%$ of mine workers exposed to vibration in gold mines. ${ }^{[6]}$ Prevalence of HAVS in the United States has been reported to be as high as $50 \%{ }^{[7]}$ Prevalence of HAVS in India is hardly documented. Dasgupta and Harrison studied 66 drillers and 35 blasters as control subjects from limestone mines. They reported a significantly higher prevalence of tingling, numbness, paresthesiae (18.2\%); pain in finger, wrists, arms, etc. $(31.7 \%)_{i}$ stiffness in hand $(13.6 \%)_{i}$ and hyperhydrosis (48.5\%) among drillers as compared to blasters. The prevalence of ulnar neuropathy and soft tissue wasting in hands was also significantly higher among the drillers. They concluded that complaints of neurological symptoms in the
Table 1: Stockholm workshop scale for classification of handarm vibration syndrome

\begin{tabular}{|c|c|c|}
\hline \multicolumn{2}{|c|}{ Stage grade } & Description \\
\hline \multicolumn{3}{|c|}{ Cold-induced Raynaud's phenomenon } \\
\hline 0 & - & No attacks \\
\hline 1 & Mild & $\begin{array}{l}\text { Occasional attacks affecting only the tips of one or more } \\
\text { fingers. }\end{array}$ \\
\hline 2 & Moderate & $\begin{array}{l}\text { Occasional attacks affecting distal or middle (rarely also } \\
\text { proximal) phalanges of one or more fingers. }\end{array}$ \\
\hline 3 & Severe & Frequent attacks affecting all phalanges or most fingers. \\
\hline 4 & Very severe & As in stage 3 , with trophic changes in the finger tips. \\
\hline \multicolumn{3}{|c|}{ Sensorineural effects } \\
\hline $0_{\text {SN }}$ & - & Exposed to vibration bur no symptoms. \\
\hline $1_{\text {SN }}$ & - & Intermittent numbness, with or without tingling. \\
\hline $2_{\text {sN }}$ & - & $\begin{array}{l}\text { Intermittent or persistent numbness, reduced sensory } \\
\text { perception. }\end{array}$ \\
\hline $3_{\text {SN }}$ & - & $\begin{array}{l}\text { Intermittent or persistent numbness, reduced tactile. } \\
\text { discrimination and or manipulative dexterity. }\end{array}$ \\
\hline
\end{tabular}

hands of drillers were significantly more prevalent than in a matched group of blasters. The combined use of nerve conduction studies to measure motor conduction velocities and the finger circumference test suggested a right median nerve pathology or carpel tunnel syndrome in the right hand; and in the left hand, a greater degree of musculoskeletal system involvement along with a left ulnar nerve lesion at the elbow. ${ }^{[8]}$ Dupuytren's contracture, a disease of the palmar fascia resulting in thickening and contracture of fibrous bands on the palmar surface of the hands and fingers, is reported to be associated with hand-arm vibration. ${ }^{[9,10]}$

Vibration transmitted to the body through the supporting surfaces such as feet, buttocks or back is known as wholebody vibration (WBV). There are various sources of WBV in the mining industry, such as the seat-transmitted vibrations from dumper, dozer, shovel, backhoes, load-haul-dump vehicles (LHD), road graders, etc.; WBV transmitted through feet while standing on or moving near vibrating machines like various types of crushers, vibrating screen or while operating certain types of loaders.

Vibration levels of various mobile mining equipments were measured by a study group in Ontario, Canada. They found that the vibration levels of LHD vehicles, dozers and graders were above the 4-hour exposure guidelines of ISO 26311:1997. ${ }^{[1]]}$ Vibration test results of measurements conducted at eight underground mine sites in another study on 16 different LHD vehicle models indicated that LHD operators were at risk to injury from whole-body vibrations. ${ }^{[12]}$ Track dozers in opencast mines were studied in Australia. It was observed that the operators were at health risk if they worked $6 \mathrm{~h}$ per day. ${ }^{[13]}$

There is strong epidemiological evidence that occupational exposure to WBV is associated with an increased risk of lower back pain, sciatic pain and degenerative changes in the spinal 
system, including lumbar intervertebral disc disorders. ${ }^{[14]}$ Which parts of the body are most likely to be injured during exposure to whole-body vibration depends on the magnitude of vibration, distribution of the motion within the body, body postures and the vibration frequency, direction and duration. Further, human body does not respond equally to all frequencies. Different parts of the body have their own resonant frequency [Table 2] and certain frequencies have no practical relevance as regard to human response.

When the organs are subjected to vibration at their specific resonance frequencies, the energy transfer from the source to the exposed part will be maximum and adverse effects will be more.

There is a shortage of conclusive evidence to establish 1) the probability and extent of vibration-induced injury and 2) a definite dose-response relationship between whole-body vibration and injury or health damage. Results from epidemiological studies, subjective data, biodynamic models and knowledge of the physical properties of the body reveal ill effects of WBV. These constitute:

- Diseases of spinal column: These are very common and associated with long-term exposure to whole-body vibration. The back is especially sensitive to the $4-8 \mathrm{~Hz}$ vibration range. WBV exposure has been linked to severe lower back pain (lumbar spine) and degeneration, bucking/ slipping of the lumbar discs. ${ }^{[7]}$ Chronic exposure to WBV takes some time before lower back problems develop. Poorly designed vehicle seats, awkward postures and manual cargo handling in addition to WBV exposure tend to aggravate lower back pain symptoms. There is a higher risk of varicose veins, menstrual disorders, proneness to abortion and hyperemesis gravidum in women exposed to WBV. Further, there is a distinct increase in blood volume during the phases of ovulation and menstruation. ${ }^{[15,16]}$

- Digestive system diseases are often observed in persons exposed to whole-body vibration over a long period of time. This is due to resonance movement of the stomach at frequencies between 4 and $5 \mathrm{~Hz}^{[1,17]}$

- Prolonged exposure to whole-body vibration at frequencies below $20 \mathrm{~Hz}$ affects cardiovascular system and results in

Table 2: Principal resonance frequencies of human body

\begin{tabular}{lcc}
\hline Posture & Part & Resonance frequency \\
\hline Standing & Whole body & $4-7 \mathrm{~Hz}$ \\
& Head and shoulder & $1-2 \mathrm{~Hz}$ \\
& Lower arm & $15-30 \mathrm{~Hz}$ \\
& Hand & $30-150 \mathrm{~Hz}$ \\
& Legs & $2-20 \mathrm{~Hz}$ \\
Sitting/reclining & Knees & $1-3 \mathrm{~Hz}$ \\
& Foot & $16-31 \mathrm{~Hz}$ \\
& Knees, abdomen and chest & $4-8 \mathrm{~Hz}$ \\
& Eye-balls & $20-25 \mathrm{~Hz}$ \\
& Skull & $50-70 \mathrm{~Hz}$ \\
\hline
\end{tabular}

hyperventilation, increase in heart rate, oxygen intake, pulmonary ventilation and respiratory rate..$^{[1,17]}$

\section{The Indian mining scenario}

The real magnitude of the problem in Indian mining industry can only be assessed with the help of a relevant database. This database should include information of employees as regard to their engagement in operations of machines/ equipments $\boldsymbol{i}_{\boldsymbol{i}}$ records of vibration monitoring, utilization and maintenance of machines/equipments, etc.

The employment figure in Indian mining sector for the year 2003 calculated on the basis of mines that reported to the regulatory authorities was 5.61 lakhs. Considering relevant information gaps, Directorate General of Mines Safety (DGMS) estimated the figure to be 1 (one) million. ${ }^{[18]}$

The Mine Labour Protection Campaign, an NGO based in the state of Rajasthan, cited the number of miners in this state alone to be 2.5 million. ${ }^{[19]}$ On the basis of this data, the number of miners in all types of mining and quarrying activity of the country may be as high as 10 million.

National Institute of Miners' Health, Nagpur, conducted vibration surveys in various mines of the country. It was found that in opencast mines, operators of heavy earth moving machineries were at greater health risk from occupational exposure to vibration. Records of two metal mines were examined to determine the percentage of mining population regularly exposed to occupational vibration [Table 3]. An average of $18 \%$ employees was found to be exposed to vibration at work.

Considering these facts and figures, the estimated number of employees regularly exposed to vibration at work in Indian mines range between 1.80 lakhs and 18 lakhs. Taking an average figure, at least 10 lakh subjects working in mines are exposed and at risk to suffer health consequences of HAV and/or WBV. Extended shift duration $(>10 \mathrm{~h}$ ) is common in unorganized and private sectors of the mining industry and pose an increased risk.

International standards and regulations are based on the research work done in developed countries, where working conditions are different and susceptibility of an individual to external stimuli may considerably vary because of ethnic,

\section{Table 3: Subjects exposed to occupational vibration in mining industry}

\begin{tabular}{lcc}
\hline Employees & Nos. & Percentage \\
\hline Total No. of employees studied & 2106 & \\
No. of employees exposed to HAV & 182 & 8.6 \\
No. of employees exposed to WBV & 194 & 9.2 \\
No. of employees exposed to HAV/WBV & 376 & 18 \\
\hline
\end{tabular}


racial and climactic factors. In a warm environment like India, the prevalence of symptom complexes for HAV is suggestive of the existence of peripheral neuropathy and musculoskeletal abnormalities rather than any peripheral circulatory disorders. ${ }^{[8]}$ The biodynamic response of Indian workers to vibration energy requires detailed studies. The regulations should be framed in consonance with this data.

\section{MEASURING VIBRATION}

Evaluation of severity of exposure depends on measurement of magnitude, frequency, direction and duration of vibration, followed by comparison with scientific guidelines. All these parameters of exposure can be measured simultaneously using modern digital vibration monitors coupled with personal computers in field conditions.

Since the magnitude of acceleration is continually changing, a single overall value is often considered indicative. The acceleration magnitude is commonly expressed as root-meansquare (R.M.S.) value of continually changing acceleration. Root-mean-square acceleration is denoted by $A_{r m s}$ and is calculated as below:

$\operatorname{Arms}=\sqrt{\frac{1}{\mathrm{~T}} \mathrm{fa}^{2}(\mathrm{t}) \mathrm{dt}}$

where $\mathrm{a}=$ frequency-weighted instantaneous acceleration in $\mathrm{m} / \mathrm{s}^{2}$

$\mathrm{t}=$ corresponding time in seconds (dt denotes the integration being performed with respect to time)

and $\mathrm{T}=$ total time period of measurement in seconds.

The daily duration of exposure can be easily recorded by the human vibration monitors during a shift of operation or a representative sample can be taken (say for $4 \mathrm{~h}$ ), which can be used for comparing with corresponding exposure limits. The duration of measurement may be for a few minutes if it characterizes a repetitive cycle of operation throughout the day.

A typical instrument uses accelerometers as sensors (transducers) which convert the mechanical energy of vibration into equivalent electrical energy and integrates the varying quantities over the period of measurement. The various factors of vibration, such as peak values, R.M.S. acceleration in defined directions ( $\mathrm{x}, \mathrm{y}$ and $\mathrm{z}$ axes) or vibration dose value, etc., thus measured can be downloaded later to a computer terminal for detailed analysis.

The instrument can be programmed to perform the following:

- Multiple frequency components of a vibration spectrum can be either accepted, attenuated or rejected using suitable electronic networks.

- Acceleration values in three mutually perpendicular axes are simultaneously obtained (i.e., up-down, side-to-side and front-to-rear) for HAV and WBV.

- The vibration results in each direction are then separately 'weighted', calculated for comparison with the appropriate HAV or WBV standard to determine if any exposure action value or exposure limit value has been exceeded.

- The result is expressed in terms of acceleration in individual axis, summation of all three axes or vibration dose value, etc., as per their definition and applicability described in reference standards.

- The run time history is recorded so that the varying magnitudes and their characteristics such as presence of shocks, etc., can be attributed to a particular operation.

\section{Legislation}

Mining being a comparatively hazardous industry, strict legislative control is desirable. In India, DGMS issued a circular under Metalliferous Mines Regulations, 1961, almost three decades ago. It reads as follows:

Vibration limits: As for the vibration limits, aim should be to take appropriate steps that will ensure desirable degree of comfort and protection required specially against:

a vibration affecting the hands and arms (vibrating tools) and

b whole-body vibration transmitted through the supporting surface.

No specific vibration limits are indicated because available scientific data is inadequate. However, for a continuous exposure, maximum permissible levels of vibration, depending on daily exposure, should be laid down in the light of current scientific knowledge, technical progress and possibilities of prevention.'[20]

Countries like U.S.A, U.K, Canada and Australia have enforced specific regulations for evaluation and control of workplace vibration based on certain standards, which are tabulated in Table 4.

ISO 5349:1986 ${ }^{[23]}$ for HAV and ISO 2631:1997 ${ }^{[24]}$ for WBV are two most important standards that are widely used for evaluation of vibration exposure.

The Bureau of Indian Standards has adopted vibration

Table 4: Standards used in U.S.A, U.K, Canada, Australia

\begin{tabular}{ll}
\hline Country & Standards \\
\hline United States of America ${ }^{[7]}$ & HAV: ANSI S3.34, ACGIH-HAV standard, and NIOSH \\
& $\# 89-106 W B V:$ ANSI S3.18 and ACGIH-WBV \\
& standard. \\
& European Union Directive 2002/44/EC for HAV and \\
U. K. ${ }^{[21]}$ & WBV. \\
Canada $^{[22]}$ & ACGIH, ANSI and ISO standards. \\
Australia $^{[23]}$ & Australian standards AS 2670 for WBV and (AS \\
& 2763) 1988 for HAV. \\
\hline
\end{tabular}


standards that are identical to corresponding ISO standards. Use of these standards is not binding on the mine management.

Standards based on substantial research done in India and other countries may help in formulating a definite regulation for the Indian mining industry.

\section{CONCLUSIONS}

1. There is lack of awareness about vibration hazard and its ill effects. This needs to be rectified.

2. The exact number of mine workers occupationally exposed to vibration is not known. Estimated number may be in lakhs.

3. There is an urgent need to investigate the population suffering from vibration exposure above safe limits and its ill effects on their health.

4. The clinical presentation of HAVS in India is not the classical VWF. Subclinical manifestations and doseresponse relationships need to be worked out for HAV and WBV in Indian miners.

5. Indian mining legislation is not specific enough to develop a definite strategy for evaluation and control of occupational vibration. Specific rules based on Indian data need to be framed.

6. Vibration monitoring should be made mandatory for all semi-mechanized and mechanized mines.

\section{REFERENCES}

1. Griffin MJ. Vibration. In: Jeanne Mager Stellman, editor. ILO Encyclopedia of occupational Safety and Health, $4^{\text {th }}$ ed. Geneva: ILO; 1998. p. 50.2-12.

2. Palmear P. Vibration (Hand Arm and Whole Body). In: Baxter PJ, Adams PH, Tar-Ching AW, Cockcroft A, Harrington JM, editors. Hunters' diseases of occupation. $9^{\text {th }}$ ed. Arnold: London; 2000. p. 307.

3. Raynaud M. Local Asphyxia and symmetrical Gangrene of the extremities (MD Thesis, Paris, 1862). In: Selected Monographs, New Sydenham Society: London; 1888.

4. Hamilton A. Effect of Air hammers on the hands of stone cutters. Industrial Hyg. Set Bull. 236, No. 19. Bureau of Labour Statistics: Washington DC, US; 1918. p. 1-4.

5. Palmear PL. Clinical picture (vascular, neurological and musculoskeletal). In: Palmear PL, Wasserman DE, editors. Hand-arm vibration: A comprehensive guide for occupational health professionals. $2^{\text {nd }}$ ed. OEM Press: Beverly Farms, MA; 1998. p. 27-43.
6. Dias B, Sampson E. Hand arm vibration syndrome: Health effects and mitigation. IOHA: Pilanesberg, South Africa; 2005. p. B1-4.

7. Donald W. Wasserman. Occupational Vibration: Are you at risk? In: Quest Technologies special report. Quest Technologies: Oconomowoc, WI 53066; 2005. p. 2.

8. Dasgupta AK, Harrison J. Effects of vibration on the hand-arm system of miners in India. Occup Med 1996;46:71-8.

9. Liss GM, Stock SR. Can Dupuytren's contracture be work-related? Review of the evidence. Am J Ind Med 1996;29:521-32.

10. Thomas PR, Clarke D. Vibration white finger and Dupuytren's contracture: Are they related? Occup Med 1992;42:155-8.

11. Eger T, Grenier S, Salmoni A. Whole-Body Vibration exposure experienced by mining equipment operators. Proceedings of $5^{\text {th }}$ Canadian Rural Health Research Society Conference and the Fourth International Rural Nurses Congress: Sudbury, ON; 2004. p. 2-4.

12. Eger T, Smets M, Grenier S. Whole-body-vibration exposure experienced during the operation of small and large load-haul-dump vehicles. Internet Publication: http:// www.nexgenergo.com.

13. Barbara M. Foster Gary and Long Ardrie. Bad vibrations: A handbook on whole body vibration exposure in mining. $1^{\text {st }}$ ed. The Joint Coal Board Health and Safety Trust: Sydney, Australia; 2001. p. 25-6.

14. Bovenzi M, Hulshof CT. An updated review of epidemiologic studies on the relationship between exposure to whole-body vibration and low back pain (1986-1997). Int Arch Occup Environ Health 1999;72:35165.

15. Abrams R. Sound and vibration in pregnancy. Seminars in Perinatology, part 11, Saunders Pub: Philadelphia; 1990. p. 273-334.

16. Wasserman DE, Wilder DG, Pope MH, Magnusson M, Aleksiev AR, Wasserman JF. Whole body vibration and occupational work hardening. J Occup Environ Med 1997;39:403-7.

17. Seidel H. Selected health risks caused by long-term whole-body vibration. Am J Ind Med 23:589-604.

18. Mining Industry in India - An overview. Directorate General of Mines Safety: Dhanbad, India; 2004. Internet Resource: http:// www.dgms.net

19. Dutt B. Organizing the unorganized. Mine Labour Protection Campaign (Monograph): Jodhpur; 2005. p. 5.

20. Kaku LC. DGMS classified circulars. Lovely Prakashan: Dhanbad; 2004. p. 604.

21. Anon. The Control of Vibration at Work Regulations 2005 No. 1093. The Stationery Office Limited: London; 2005. http:// www.opsi.gov.uk

22. OHS Guidelines for Noise, Vibration, Radiation and Temperature Part 7 - Division 2 - Vibration Exposure. Crown Publications: Ontario; 2005. http:// www.worksafebc.com.

23. IS0 2631-1:1997. Mechanical vibration and shock - Evaluation of human exposure to whole-body vibration-Part 1: General requirements. International Organization for Standardization: Switzerland; 1997.

24. IS0 5349:1986.Mechanical Vibration - Guidelines for the Measurement and the Assessment of Human Exposure to Hand Transmitted Vibration. International Organization for Standardization: Switzerland; 1986.

Source of Support: Nil, Conflict of Interest: None declared. 